\title{
Characterization and application of cellulose acetate synthesized from sugarcane bagasse
}

\author{
R.G. Candido ${ }^{\mathrm{a}, *}$, G.G. Godoy ${ }^{\mathrm{a}}$, Adilson R. Gonçalves ${ }^{\mathrm{b}}$ \\ a Departamento de Biotecnologia, Escola de Engenharia de Lorena, Universidade de São Paulo, CEP 12.602-810, Lorena, SP, Brazil \\ b Instituto de Pesquisa em Bioenergia, UNESP, Rio Claro, SP, Brazil
}

\section{A R T I C L E I N F O}

\section{Article history:}

Received 13 January 2017

Received in revised form 16 March 2017

Accepted 17 March 2017

Available online 18 March 2017

\section{Keywords:}

Cellulose acetate

Sugarcane bagasse

Cellulose acetate application

Cellulose derivative

Membrane synthesis

\begin{abstract}
A B S T R A C T
The synthesis and application of cellulose acetate (CA) from sugarcane bagasse were investigated. Firstly, cellulose was extracted by a sequential treatment with $\mathrm{H}_{2} \mathrm{SO}_{4}(10 \% \mathrm{v} / \mathrm{v}), \mathrm{NaOH}(5 \% \mathrm{w} / \mathrm{v})$, EDTA $(0.5 \% \mathrm{w} / \mathrm{V})$, and $\mathrm{H}_{2} \mathrm{O}_{2}(5 \% \mathrm{v} / \mathrm{v})$, and characterized by X-ray diffraction (DRX). After the acetylation of the extracted cellulose, CA was characterized using Fourier transform infrared spectroscopy (FTIR), differential scanning calorimetry (DSC), and thermogravimetry analysis (TGA), and was applied in the membrane production. The membranes were analyzed by DSC and atomic force microscopy (AFM), and tested in the flux of water vapor to determinate the best conditions for membrane manufacturing. FTIR analysis proved the replacement of free $\mathrm{OH}$ groups by acetyl groups, and the thermal analysis showed that sugarcane bagasse CA possessed thermal properties compared to commercial grade CA. The best conditions to prepare membrane were: $3 \%(\mathrm{w} / \mathrm{v})$ of polymer/solvent relation, $10 \mathrm{~min}$ of solvent evaporation time, and $20^{\circ} \mathrm{C}$ as temperature for the coagulation bath. These results show that CA can be successfully synthesized from sugarcane bagasse and applied in membrane preparation.
\end{abstract}

(C) 2017 Elsevier Ltd. All rights reserved.

\section{Introduction}

Agricultural commodities are the key raw materials available to humanity for the sustainable production of numerous industrial and non-food consumer products, which led to the growing interest in the chemistry of compounds derived from biomass, and to exertions that aim at the use of agricultural wastes as alternative sources of chemicals, energy and materials. A positive feature of the trend in use of agricultural wastes, such as sugarcane bagasse, wheat and rice straw, cereal straws, and corn stove, as a feedstock for value-added products is that they are fairly free from wide price fluctuations, and are not subject to the debates about the use of agricultural food materials, as grains and cereals, for the production of chemicals, polymers and materials (Heguaburu et al., 2012; Shaikh, Pandare, Nair, \& Varma, 2009).

The main structural component of the agricultural wastes is cellulose turning this compound into the most abundant natural polymer on earth (Habib, Lucia \& Rojas, 2010). The primary

\footnotetext{
* Corresponding author.

E-mail addresses: rafaelgcandido85@gmail.com, rafatrakinas@yahoo.com.br (R.G. Candido), guilhermeggodoy@gmail.com (G.G. Godoy), adilson@ipben.unesp.br (A.R. Gonçalves).
}

structure of cellulose is represented by a linear polymer of $\beta$ glucopyranoside residues, linked by $1-4-\beta$-glycosidic bonds. The polymerization degree is commonly very high reaching 20.000 residues in one chain, depending on the source of extraction. The residues are rotated $180^{\circ}$ towards each other and, thus, the repeated unit in cellulose is a cellobiose residue rather than a glucose residue as in the starch structure (Lavoine, Desloges, Dufresne, \& Bras, 2012).

Each unit of anhydroglucose possesses three free hydroxyl groups with distinct reactivity, secondary $\mathrm{OH}$ at the $\mathrm{C}-2$, secondary $\mathrm{OH}$ at the $\mathrm{C}-3$, and primary $\mathrm{OH}$ at the $\mathrm{C}-6$ position $^{4}$. Diverse derivative compounds can be synthesized from cellulose replacing these free $\mathrm{OH}$ groups for other chemical groups, such as methyl, acetyl, carboxymethyl, etc (Lewin \& Goldstein, 1991). The conversion of cellulose into derivative compounds with high economic value has gained considerable attention in the fields of green and sustainable chemistry, and has provided the development of friendly environmental technologies (Chheda, Huber, \& Dumesic, 2007). The synthesis of cellulose derivatives requires cellulose of high purity. The remaining amount of lignin and hemicellulose must be reduced to a minimum (Ek, Gellerstedt, \& Henriksson, 2009). Industrially, cellulose acetate (CA) is one of the most important cellulose esters for being originated from a renewable source, biodegradable, 
non-toxic, low cost, and low inflammable (Buchanan Gardner, \& Komarek, 1993; Gaana et al., 2011; Sun, Lu, Zhang, Tian, \& Zhang, 2013). Recently, Global Industry Analysis reported that the worldwide market of cellulose acetate is projected to about 1.05 million metric tons by 2017 , and its estimated price is around $\$ 1.80 / \mathrm{lb}$ (www.strategyr.com; Cheng, Dowd, Selling, \& Biswas 2010). CA is produced by the reaction of cellulose with acetic acid, a surplus of acetic anhydride, and sulfuric acid as the catalyst in a two-step acetylation process, followed by hydrolysis reaction to produce a CA with the desirable degree of substitution (DS), about 2.45-2.5, which grants high solubility (in several types of solvent systems) and good melt properties. These properties facilitate CA's utilization in a variety of consumer products (Cao et al., 2007; Fischer et al., 2008; Puls, Wilson, \& Hölter, 2011; Steinmeier, 2004).

Cellulose acetate is widely applied in textiles, in cigarette filters to absorb vapors and accumulate particulate smoke components, in surface coatings and inks as an additive, and in photographic negatives, motion picture film (celluloid), microfilm, microfiche and audio tape as a carrier (Cheng et al., 2010; Gedon \& Fengl, 1993). Nevertheless, the main application of cellulose acetate is in the production of membranes. CA is adequate as membrane materials, because of the advantages such as moderate flux, high salt rejection properties, cost effectiveness, relatively easy manufacture, and non-toxicity (Kamal, Abd-Elrahim, \& Lotfy, 2014). Cellulose acetate membranes are used, for example, in the water desalination (Haddad, Ferjani, Roudesli, \& Deratani, 2004), in the hemodialysis process (Liao et al., 2005), and in the controlled drug release (Wang et al., 2012).

The most traditional material resources for the industrial acetylation of cellulose are wood and cotton (Rodrigues Filho et al., 2008; Steinmeier, 2004). However, regarding its availability in large amounts as a result of its widespread cultivation on a global scale, agricultural wastes have become an attractive renewable resource for the synthesis of cellulose acetate (Fan, Liao, Fang, Luo, \& Song, 2014). The major barriers to produce cellulose-based products from agricultural residues are the heterogeneity of the raw material, the experimental conditions reproducibility, the heterogeneous phase of the synthesis reaction, the difficulty of purification, the effluent disposal, and the control of the product quality (Ek et al., 2009).

Sugarcane is the most harvested crop in the world. As consequence, its residual bagasse is the most abundant agricultural waste (Santos, Ely, Szklo, \& Mafrini, 2016). The sugarcane bagasse (SCB) is the solid and fibrous fraction which remains from usual milling of sugarcane (Bizzo, Lenço, Carvalho, \& Veiga, 2014). Brazil produces about one third of global sugarcane bagasse and generates 200 million tons of this waste (www.unicadata.com.br). It is commonly used as energy and electricity source in the Brazilian sugarcane mills (Dantas, Legey, \& Mazzone, 2013). However, the recent advances on biotechnology and the development of the biorefinery concept expanded the possibilities of bagasse application (Cherubini, 2010). The main conclusion of the studies about new use of sugarcane bagasse is that the materials and chemical products stay ahead of electricity and fuels (Fahd, Fiorentino, Mellino, \& Ulgiati, 2012; Luo, Voet, \& Huppes, 2010).

The present work aimed at the synthesis, characterization and application of cellulose acetate from sugarcane bagasse. The synthesis of CA was performed using the homogeneous process and CA was characterized by its degree of substitution and percentage of acetyl groups, infrared spectroscopy (FTIR), differential scanning calorimetry (DSC), and thermogravimetry analysis (TGA) techniques. Additionally, CA was applied in the production of membrane, which was characterized by the measurement of porosity and atomic force microscopy (AFM), and tested in the flux of water vapor.

\section{Materials and methods}

\subsection{Materials}

Chemicals used in this work were of analytical grade. They were purchased from Aldrich Co, and used without any further purification.

\subsection{Sugarcane bagasse}

Sugarcane bagasse was courtesy of the sugar and ethanol mill Usina de Açúcar, Álcool e Biodiesel Vale do Rosário located in Orlândia City, São Paulo State, Brazil. The material was dried at room temperature until the dry matter content was above $10 \%$ of moisture content and placed in plastic bags until used.

\subsection{Cellulose extraction}

\subsubsection{Acid treatment}

Acid pretreatment was carried out in $4 \mathrm{~L}$ glass beaker flask with $10 \%(\mathrm{v} / \mathrm{v}) \mathrm{H}_{2} \mathrm{SO}_{4}$ and $1 / 10(\mathrm{w} / \mathrm{v})$ solid/liquid ratio of dry SCB loading under stirring in thermal bath with heating ramp for $40 \mathrm{~min}$, and when the temperature reached $100^{\circ} \mathrm{C}$, the reaction time was recorded. At the end of reaction, the solid fraction was separated from liquid fraction by vacuum filtration, and washed with distilled water until the $\mathrm{pH}$ was neutral. The material was dried at room temperature and stored for subsequent chemical analysis.

\subsubsection{Alkaline treatment}

Alkaline pretreatment was carried out in $4 \mathrm{~L}$ polypropylene beaker flask with $5 \%(\mathrm{w} / \mathrm{v}) \mathrm{NaOH}$ and $1 / 10(\mathrm{w} / \mathrm{v})$ solid/liquid ratio of dry acid pretreated material loading under stirring in thermal bath with heating ramp for $60 \mathrm{~min}$, and when the temperature reached $100^{\circ} \mathrm{C}$, the reaction time was recorded. Subsequently, the solid fraction was separated from liquid fraction by vacuum filtration, and washed with distilled water until the $\mathrm{pH}$ was neutral. The material was dried at room temperature and stored for subsequent chemical analysis.

\subsubsection{Chelating}

The chelating process was carried out using 0.5\% EDTA for $30 \mathrm{~min}$ at $70^{\circ} \mathrm{C}$ in a polypropylene bag with a final concentration of $10 \%(w / v)$. At the end of reaction, the material was filtered and washed with distilled water at $70^{\circ} \mathrm{C}$.

\subsubsection{Bleaching}

The chemical bleaching was carried out in polypropylene bags with $5 \%(\mathrm{v} / \mathrm{v}) \mathrm{H}_{2} \mathrm{O}_{2}, 0.1 \% \mathrm{MgSO}_{4}$ in for $45 \mathrm{~min}$, at $70^{\circ} \mathrm{C}$ under medium consistency of $5 \%(\mathrm{w} / \mathrm{v})$ and $\mathrm{pH} 12$ (adjusted with concentrated $\mathrm{NaOH}$ solution). At the end of the process, the material was washed with distilled water at $70^{\circ} \mathrm{C}$ until the $\mathrm{pH}$ reached a value of 7.

\subsection{Cellulose acetate synthesis}

For the synthesis of CA, $24 \mathrm{~mL}$ of glacial acetic acid was added to $10 \mathrm{~g}$ of sugarcane straw cellulose, and this mix was stirred at $37.8^{\circ} \mathrm{C}$ for $1 \mathrm{~h}$. Subsequently, it was aggregated $40 \mathrm{~mL}$ of glacial acetic acid

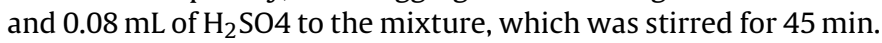
After that, the mixture was cooled to $18.3^{\circ} \mathrm{C}$ and $28 \mathrm{~mL}$ of acetic anhydride and $0.6 \mathrm{~mL}$ of $\mathrm{H}_{2} \mathrm{SO}_{4}$ were added. Then, the temperature was elevated to $35^{\circ} \mathrm{C}$ and the mixture was stirred for $1.5 \mathrm{~h}$. Then, a solution of $10.0 \mathrm{~mL}$ of water and $20 \mathrm{~mL}$ of glacial acetic acid was added in small portions for $1 \mathrm{~h}$ under stirring. Finally, the material 
obtained was washed with distilled water until pH 7.0 (Rodrigues Filho, Silva, Meireles, Assunção, \& Otaguro, 2005).

\subsubsection{Determination of the degree of substitution (DS) of CA}

$0.1 \mathrm{~g}$ of cellulose acetate was added to $5 \mathrm{~mL}$ of $0.25 \mathrm{M} \mathrm{NaOH}$ and $5 \mathrm{~mL}$ of ethanol. This mixture was left to stand for $24 \mathrm{~h}$. In the next step, $10 \mathrm{~mL}$ of $0.25 \mathrm{M} \mathrm{HCl}$ was added to the mixture and the system was left to stand for $30 \mathrm{~min}$. Then, the mixture was titrated by a standard $0.25 \mathrm{M} \mathrm{NaOH}$ solution, using phenolphthalein as indicator. This procedure was carried out in triplicate. The percentage of acetyl groups (\% AG) was calculated by the following equation (Kelley, Puleo, \& Paul, 1989):

$\% \mathrm{GA}=\{[(\mathrm{Vbi}+\mathrm{Vbt}) * \mu \mathrm{b}-(\mathrm{Va} * \mu \mathrm{a})] * \mathrm{M} * 100\} / \mathrm{mac}$

where:

Vbi: volume of $\mathrm{NaOH}$ added to the system (L)

Vbt: volume of $\mathrm{NaOH}$ spent in titration (L)

$\mu b$ : $\mathrm{NaOH}$ concentration (M)

Va: volume of $\mathrm{HCl}$ added to the system (L)

$\mu \mathrm{a}: \mathrm{HCl}$ concentration $(\mathrm{M})$

M: molar weight of acetyl group $\left(43 \mathrm{~g} \mathrm{~mol}^{-1}\right)$

mac: weight of cellulose acetate sample $(\mathrm{g})$

\subsection{Membrane preparation}

It was carried out a variation of parameters in the synthesis of the membrane in order to determine the best conditions of the process. Table 1 presents the evaluated parameters in the preparation of the cellulose acetate membranes.

Cellulose acetate membranes were prepared by the phase inversion method. At first $1.5 \mathrm{~g}$ of cellulose acetate were mixed with $50 \mathrm{~mL}$ of dichloromethane and stirred for $5 \mathrm{~h}$. The mixture was sonicated for $10 \mathrm{~min}$ to remove air bubbles. Subsequently, the cast solution was spread on a glass board in a thickness of $400 \mu \mathrm{m}$ followed by the solvent evaporation process. After that the glass board was immersed in the coagulation bath (distilled water) for $2 \mathrm{~h}$ in order to complete the phase inversion process and to the release of the membrane from the board glass surface.

\subsubsection{Porosity measurement}

In order to evaluate porosity of the membrane, it was initially impregnated with distilled water then weighed after wiping superficial water. Subsequently, the wet membrane was placed in an air-circulating oven at $80^{\circ} \mathrm{C}$ for $24 \mathrm{~h}$ to be completely dried. In the final step, the dry membrane was weighed. The porosity of membranes was calculated using the following equation (Zheng, Wang, Yang, \& Cui, 2006):

$\mathrm{P}(\%)=\left[\left(\mathrm{Q}_{0}-\mathrm{Q}_{1}\right) / \mathrm{A} * \mathrm{~h}\right] \times 1000$

where:

$\mathrm{P}:$ membrane porosity

$\mathrm{Q}_{0}$ : weight of wet membrane $(\mathrm{g})$

$\mathrm{Q}_{1}$ : weight of dry membrane $(\mathrm{g})$

A: membrane surface area $\left(\mathrm{cm}^{2}\right)$

$\mathrm{H}$ : membrane thickness ( $\mathrm{mm}$ )

\subsubsection{Flux of water vapor}

The water vapor flux through the membrane was measured by the Payne's cup technique. The membrane was cut into the shape of a disk, with the same diameter of the Payne's cup. Water was added to the cup and the disk was placed onto the cup's support. The system was weighed and placed in a desiccator, and was weighed at every hour, for $9 \mathrm{~h}$, which was sufficient for reaching the steady-state regimen. Weight-loss was calculated according to the following equation (Rodrigues Filho et al., 2000):

$\mathrm{J}=\Delta \mathrm{m} /(\Delta \mathrm{t} * \mathrm{~A})$

where:

$\mathrm{J}$ : water vapor flux $\left(\mathrm{mg} \mathrm{h}^{-1} \mathrm{~cm}^{-2}\right)$

$\Delta \mathrm{m}$ : mass difference $(\mathrm{mg})$

$\Delta \mathrm{t}$ : time difference $(\mathrm{h})$

A: membrane surface area $\left(\mathrm{cm}^{2}\right)$

\subsection{Analyticals}

\subsubsection{Chemical characterization}

Cellulose was chemically characterized in order to determinate the content of cellulose, hemicellulose and lignin. This technique uses concentrated $\mathrm{H}_{2} \mathrm{SO}_{4}$ to break the material structure, hydrolisate and solubilize the components of the cell wall.

Cellobiose, glucose and hydroxymethylfurfural concentrations were used to calculate the content of cellulose (Eq. (4)), whereas xylose, arabinose, acetic acid and furfural concentrations were used to determine the content of hemicellulose (Eq. (5)).

$\mathrm{C}_{\text {cellulose }}=0.95 * \mathrm{C}_{\text {cellobiose }}+0.90 * \mathrm{C}_{\text {glucose }}+1.29 * \mathrm{C}_{\mathrm{HMF}}$

$$
\begin{aligned}
& \mathrm{C}_{\text {hemicellulose }}=0.88 * \mathrm{C}_{\text {xylose }} \\
& \quad+0.88 * \mathrm{C}_{\text {arabinose }}+1.38 * \mathrm{C}_{\text {furfural }}+0.70 * \mathrm{C}_{\text {aceticacid }}
\end{aligned}
$$

The concentrations of the sugars, organic acid, dehydration products were measured by HPLC.

To determine the soluble lignin fraction, a solution with $5 \mathrm{~mL}$ aliquot of the hydrolysate was prepared. This was adjusted to $\mathrm{pH}$ 12 with $6.5 \mathrm{M} \mathrm{NaOH}$ in a total volume of $100 \mathrm{~mL}$. The solution was then analyzed by UV-spectroscopy (Perkin Elmer LAMBDA 25) at $280 \mathrm{~nm}$ and the concentration was calculated using Eq. (6).

$\mathrm{C}_{\text {lig }}=\left(\mathrm{A}_{\text {lig280 }}-\mathrm{Apd}_{280}\right) / \varepsilon_{\text {lig }}$

where:

$\mathrm{C}_{\text {lig }}$ : concentration of soluble lignin $\left(\mathrm{g} \mathrm{L}^{-1}\right)$;

$\mathrm{A}_{\text {lig280 }}$ : absorbance of the solution at $280 \mathrm{~nm}$;

$A_{\text {pd280 }}$ : absorbance of sugar-degradation products (furfural and HMF);

$\mathrm{A}_{\mathrm{pd} 280}=\mathrm{C}_{1} * \varepsilon_{1}+\mathrm{C}_{2} * \varepsilon_{2}$

where:

$\mathrm{C}_{1}$ : furfural concentration $\left(\mathrm{g} \mathrm{L}^{-1}\right)$

$\mathrm{C}_{2}$ : HMF concentration $\left(\mathrm{g} \mathrm{L}^{-1}\right)$

$\varepsilon_{1}$ : furfural absorptivity at $280 \mathrm{~nm}\left(\varepsilon_{1}=146.85 \mathrm{~cm}^{-1} \mathrm{~g}^{-1} \mathrm{~L}\right)$

${ }_{\varepsilon 2}$ : HMF absorptivity at $280 \mathrm{~nm}\left(\varepsilon_{2}=114 \mathrm{~cm}^{-1} \mathrm{~g}^{-1} \mathrm{~L}\right)$

elig: lignin absorptivity at $280 \mathrm{~nm}\left(\varepsilon_{\text {lig }}=19.1 \mathrm{~cm}^{-1} \mathrm{~g}^{-1} \mathrm{~L}\right.$ ) (Rocha, Martín, Silva, Gómez, \& Gonçalves, 2012).

The total content of lignin was calculated by the sum of soluble and insoluble (material not dissolved by acid discounted by the content of the ashes). The amount of ashes was determined by the incineration of the material not dissolved by acid followed by gravimetric quantification.

\subsubsection{Viscosity}

Viscosity of the extracted cellulose was measured according to TAPPI test method T-230 (TAPPI, 1994).

\subsubsection{Fourier transform infrared spectroscopy (FTIR)}

Samples of extracted sugarcane bagasse cellulose and CA were analyzed by FTIR in order to compare the structure of the materials before and after the synthesis of cellulose derivative. Initially, the 
Table 1

Evaluated conditions for the synthesis of cellulose acetate membranes.

\begin{tabular}{|c|c|c|c|}
\hline Membrane & Polymer/solvent relation (\%w/v) & Time for solvent evaporation ( $\mathrm{min}$ ) & Temperature of coagulation bath $\left({ }^{\circ} \mathrm{C}\right)$ \\
\hline M1 & 3 & 5 & 5 \\
\hline M2 & 3 & 5 & 20 \\
\hline M3 & 3 & 10 & 5 \\
\hline M4 & 3 & 10 & 20 \\
\hline
\end{tabular}

samples were dried at $60^{\circ} \mathrm{C}$ and subsequently cooled for $30 \mathrm{~min}$ in a vacuum desiccator in the presence of $\mathrm{P}_{2} \mathrm{O}_{5}$. For the analysis, pellets containing $250 \mathrm{mg}$ of dry $\mathrm{KBr}$ and $1.5 \mathrm{mg}$ of sample were prepared, by compressing at $10 \mathrm{kgf} \mathrm{cm}^{-1}$ under vacuum. The same samples were prepared as reference, containing only KBR. The spectra were measure in the region $4000-400 \mathrm{~cm}^{-1}$ in a spectrophotometer Spectrum One Perkin Elmer. The resulting spectra were normalized for better comparison.

\subsubsection{Differential scanning calorimetry (DSC) and}

thermogravimetry analysis (TGA)

DSC and TGA were performed in order to determine the thermal properties of both cellulose acetate and membrane. Initial weight of CA and membrane samples of $20 \mathrm{mg}$ were subjected to simultaneous DSC and TGA in a nitrogen atmosphere $(100 \mathrm{~mL} / \mathrm{min})$, at a heating rate of $10^{\circ} \mathrm{C} / \mathrm{min}$ and a temperature range of $30^{\circ} \mathrm{C}-650^{\circ} \mathrm{C}$ using a TA-Instruments SDT Q600.

\subsubsection{Atomic force microscopy (AFM)}

To determinate the surface morphology of the membrane, small squares $\left(1 \mathrm{~cm}^{2}\right)$ were cut for the production of images of $1 \mu \mathrm{m} \times 1 \mu \mathrm{m}$. Atomic force microscopy was performed by Bucker ${ }^{\mathrm{TM}}$ scanning probe-optical microscope (Dimension Icon model).

\subsection{6. $X$-ray diffraction $(X R D)$}

X-ray diffraction analysis was performed with SCB and isolated cellulose to determine the change in the crystallinity of the cellulose after the isolation processes. It was used a Shimadzu XRD-6000 diffractometer. Wide-angle-X-ray intensities were recorded from $5^{\circ}$ to $80^{\circ}$ in $2 \theta$. The crystallinity index (IC) was calculated by the following equation (Thygesen, Oddershede, Lilholt, Thomsen, \& Stahl, 2005).

$\mathrm{CrI}=\left[\left(\mathrm{I}_{200}-\mathrm{I}_{\mathrm{am}}\right) / \mathrm{I}_{200}\right] * 100$

where:

$\mathrm{I}_{200}$ : Intensity of the peak in the crystalline plan $200\left(2 \theta=22.6^{\circ}\right)$; $I_{a m}$ : Intensity of the peak in the amorphous portion $\left(2 \theta=19.0^{\circ}\right)$.

\section{Results and discussion}

\subsection{Cellulose extraction}

The chemical composition of the sugarcane bagasse used as raw material in this work was $46.42 \%$ of cellulose, $28.09 \%$ of lignin, $23.97 \%$ of hemicellulose, and $1.52 \%$ of ashes. The final chemical composition of the cellulose extracted from sugarcane bagasse was $85.78 \%$ of cellulose, $7.90 \%$ of hemicellulose and $5.05 \%$ of lignin.

After all stages, a material with high purity in relation to cellulose was obtained demonstrating that the performed conditions were suitable and efficient. Another result that corroborates with the efficiency of the extraction process is the total cellulose loss. Only $23 \%$ of the initial cellulose content was removed during the extraction process, whereas the total removal of hemicellulose was $86 \%$, and lignin was $92 \%$.

The acid treatment was responsible for the highest hemicellulose solubilization. About $70 \%$ of the initial content of this component was solubilized in this stage. Actually, hemicellulose was the only component that presented a massive removal in the treatment with $\mathrm{H}_{2} \mathrm{SO}_{4}$, confirming that there is preferably removal of hemicelluloses in acidic medium. The hemicellulosic structure is branched and amorphous which facilitates its acid hydrolysis. Compared with the present work, other works reported larger hemicellulose removal after acid treatment of a lignocellulosic biomass. According to the results published by Martin, Volvok, Rozhkova, Puls, and Sinitsyn (2015), the hemicellulose content decreased about $95 \%$ after SCB acid treatment. The acid treatment of corn stover conducted by Lee, Kim, Jang, Lee, and Park (2015) was able to remove $77.3 \%$ of hemicellulose initial content. Both works performed the acid treatment in higher temperatures than this work showing that the temperature is a key factor for hemicellulose solubilization in acid medium, as previously demonstrated (Silverstein, Chen, Sharma-Shivappa, Boyette, \& Osborne, 2007). On the other hand, the higher severity of the acid treatment led to the intensification of the hydrolysis reaction in the cellulose polymeric chain, culminating in higher cellulose solubilization. Such fact is completely undesirable considering the goals of the present work, as higher cellulose removal means lower yield of cellulose extraction. Therefore, despite lower hemicellulose removal, the conditions in which the acid pretreatment was carried out in our work were considered quite appropriated. Moreover, cellulose was remarkably preserved. Only $15.87 \%$ of the cellulose initial content was solubilized in the best time reaction $(40 \mathrm{~min})$ for the SCB acid treatment.

The highest lignin removal occurred in the treatment with $\mathrm{NaOH}$. Approximately, $68 \%$ of lignin initial content was removed in this stage. The great solubilization of lignin in alkaline medium is assigned to the intensive dissolution of lignin structure in alkaline conditions. The alkali ruptures the intramolecular crossed bonds between lignin and hemicellulose, increasing the material porosity and the alkali access to the lignin. The alkaline treatment was not quite effective in removing the carbohydrates, principally cellulose. This fact confirms that, theoritically, lignin is the most removed component in alkaline medium.

Cellulose was preserved in the bleaching stage; only hemicellulose (29\%) and, mainly, lignin (39\%) were solubilized in this process. Hence, lignin was the most solubilized component in the end of overall extraction process. As consequence of the great total lignin removal, the extracted cellulose presented significant visual brightness, since the chromophore compounds, which provide the dark color of unbleached cellulose, are generated, mainly, from the lignin structure. Another important aspect was the total cellulose loss after the three treatments, which achieved a value of $23 \%$. This result demonstrates that the conditions for performing the overall extraction process were very effective in preserving cellulose.

An important characteristic of the extracted cellulose was the viscosity. It was obtained a viscosity value of $6.26 \mathrm{mPa} * \mathrm{~s}$. This value is lower than, for example, the viscosity of cellulose extracted from wood, showing that the polymeric chain of the sugarcane bagasse cellulose is not very lengthy. Nevertheless, this is a positive aspect for the application of cellulose in the synthesis of cellulose derivatives, such as cellulose acetate. Low viscosity increases the accessibility to the cellulosic chain improving the yield of the derivation process (Kvarnlof, Germgard, Jonsso, \& Soderlund, 2006). 
Extracted cellulose presented a crystallinity index (CrI) of $51.93 \%$ and sugarcane bagasse presented an $\mathrm{CrI}$ of $44 \%$. This higher $\mathrm{CrI}$ for SCBC is result of a larger exposure of cellulose in SCBC than in sugarcane bagasse. Considering that cellulose is the single structural component that presents crystallinity, it was expected that the crystallinity index ( $\mathrm{CrI}$ ) value was close to cellulose content. Indeed, this happened to sugarcane bagasse, which IC was $43.9 \%$ whereas the cellulose content was $46.4 \%$. The small difference is attributed to the amorphous portion of the cellulose chain. Differently, this behavior was not observed for SCBC. The content of cellulose $(85.7 \%)$ was quite higher than $\mathrm{CrI}$ (51.9\%) demonstrating that the process to extract cellulose affected extensively the nature of cellulose by modifying its structure and morphology.

Jiang et al. (2013)Jiang, Fang, Li, Luo, and Fan (2013) observed an increase of CrI after dilute acid-pretreatment of SBC. The authors reported that the amorphous components were more removed than crystalline cellulose because the inter- and intrachain hydrogen-bonding in cellulose fibrils were not broken. In opposite, Maryana, Marifatun, Wheni, Satriyo, and Rizal (2014) reported a decrease in the intensity of the peak correlated with the cellulose crystallinity in a sodium hydroxide treated sugarcane bagasse. According to the authors, in alkaline medium occurs the rearrangement of the cellulose chain, transforming it from crystalline to amorphous. Thus, it is possible to suggest that the alkaline treatment stage was the principal responsible for the decrease of $\mathrm{CrI}$ in our work.

\subsection{Cellulose acetate characterization}

The synthesized cellulose acetate presented a DS of 2.52 and a percentage of acetyl groups of $43.50 \%$, characterizing it as a triacetate. The high lignin solubilization in the extraction process was extremely important to achieve a high DS. Lignin competes with cellulose for the acetylation reactants and, consequently, a high amount of lignin could decrease the yield of the acetylation process.

The DS value also confirmed the importance of the low viscosity, as mentioned previously. The higher accessibility to the cellulose chain, as consequence of the low viscosity, increased the efficiency of the activation stage in the acetylation process. There was a higher access of the acetic anhydride to the free $\mathrm{OH}$ groups of cellulose, improving the activation of cellulose for the acetylation process second stage. The activation stage is crucial to the synthesis of cellulose acetate with $\mathrm{DS} \geq 2.0$.

The comparison of CA and extracted cellulose spectra is exhibited in Fig. 1. Five main changes in the CA structure were observed:

1. Decrease of the band in $3400 \mathrm{~cm}^{-1}$, corresponding to the stretching of $\mathrm{OH}$ groups of cellulose as result of the free $\mathrm{OH}$ group replacement for the acetyl groups (Rodrigues Filho et al., 2008);

2. Rise of the band in $1750 \mathrm{~cm}^{-1}$, corresponding to the stretching of $\mathrm{C}=\mathrm{O}$ bond of ester carbonyl, which is present in the structure of the acetyl groups (Rodrigues Filho et al., 2008);

3. Decrease of the band in $1650 \mathrm{~cm}^{-1}$, corresponding the absorption of water (Barud et al., 2008);

4. Rise of the band in $1360 \mathrm{~cm}^{-1}$, corresponding to the vibration of $\mathrm{C}-\mathrm{H}$ bond, which is present in the structure of the acetyl groups (Cao et al., 2007);

5. Rise of the band in $1220 \mathrm{~cm}^{-1}$, corresponding to the vibration of $\mathrm{C}-\mathrm{O}$ bond, which is responsible for the link between cellulose and acetyl group (Cao et al., 2007);

The thermal characterization of CA by DSC and TGA is illustrated in the graphics of Fig. 2. In the analysis of the DSC was observed an endothermic peak at $32{ }^{\circ} \mathrm{C}$, which represents the glass transition $\left(\mathrm{T}_{\mathrm{g}}\right)$ of the material. This $\mathrm{T}_{\mathrm{g}}$ value for the CA synthesized from sugarcane bagasse is practically the same to the value reported to a commercial grade $\mathrm{CA}\left(\mathrm{T}_{\mathrm{g}}=33^{\circ} \mathrm{C}\right)$ (Candido, 2015). Considering that the commercial grade CA is $100 \%$ pure, it can be inferred that the presence of lignin and hemicellulose in the composition of sugarcane bagasse CA did not alter significantly this thermal property. On the other hand, the presence of other compounds affected the determination of the CA thermal decomposition temperature. As demonstrated by DSC analysis, the degradation of the CA chain starts at $300^{\circ} \mathrm{C}$, but it does not have a defined peak like the other thermal events, because it also represents the degradation of lignin and hemicellulose. The exothermic peak at $200^{\circ} \mathrm{C}$ is associated to the crystallization of the analyzed material (He, Zhang, Cui, \& Wang, 2009). The CA was not totally crystalline, since the sugarcane bagasse cellulose presented some amorphous portion. Thus, the crystallization process during the analysis was attributed to this amorphous portion. The endothermic peak at $217^{\circ} \mathrm{C}$ represents the thermal decomposition of the non-acetylated cellulose (Barud et al., 2008).

TGA results showed three main thermal events: desorption of water adsorbed in CA structure and evaporation of volatile compounds (between 30 and $200^{\circ} \mathrm{C}$ ), pyrolitic decomposition of CA polymer chain skeleton followed by deacetylation together with the decomposition of hemicellulose and lignin chains (between 200 and $380^{\circ} \mathrm{C}$ ), and carbonization of degradation products (between 380 and $600^{\circ} \mathrm{C}$ ) (Shaikh et al., 2009). Desorption of water represented only $6 \%$ of total loss of mass in the TGA analysis. This result is lower than reported by other works (Rodrigues Filho et al., 2008), and confirms the result observed in the FTIR analysis, which pointed the decrease in the adsorbed water content. The decomposition and deacetylation of the polymeric chain represented $67 \%$ of the loss of mass, and $9 \%$ of the mass loss was caused by the carbonization of degradation products.

\subsection{Cellulose acetate application in membrane synthesis}

\subsubsection{AFM}

The AFM images of the four membrane surfaces are shown in Fig. 3. It was observed large dark regions on the surface of all membranes. This dark area represents the valleys or membranes porous, which indicates that the four membranes have porous in their structure. It was also noted some bright areas which correspond to the highest points or nodules and do not have porous (Rajesh, Maheswari, Senthilkumar, Jayalakshmi, \& Mohan, 2011). The membranes presented a rough surface. This characteristic, combined with the porosity, allows the membrane operates with high flux (Mansourpanah, Madaeni, Rahimpour, \& Farhadian, 2009).

This result is different when compared to pure cellulose acetate membranes. The surface of the membrane prepared from pure CA possesses a flat and dense surface and its morphology surface changes to rough and porous only if additives are added to the casting solution (Ghaemi et al., 2012). Additives were not used in the present work. However, the CA was not totally pure due to the existence of lignin and hemicellulose in its structure. This means that these compounds acted as additives and contributed to the synthesis of porous and rough membranes instead of dense and flat.

\subsubsection{Porosity}

The porosity measurement determined the percentage of the membrane structure that is porous, and not the size of the porous. Membrane M1 presented a porosity of $18.52 \pm 0.64 \%$, M2 of $23.70 \pm 0.75 \%$, M3 of $19.81 \pm 3.06 \%$, and M4 of $13.70 \pm 1.79 \%$. These porosity results confirm which was observed in AFM analysis, the four membranes possess porous in their structures. The percentage of porosity presented by membranes M1-M3 were not quite different. On the contrary, membrane M4 presented very lower porosity than the other membranes. Considering the porosity results and 


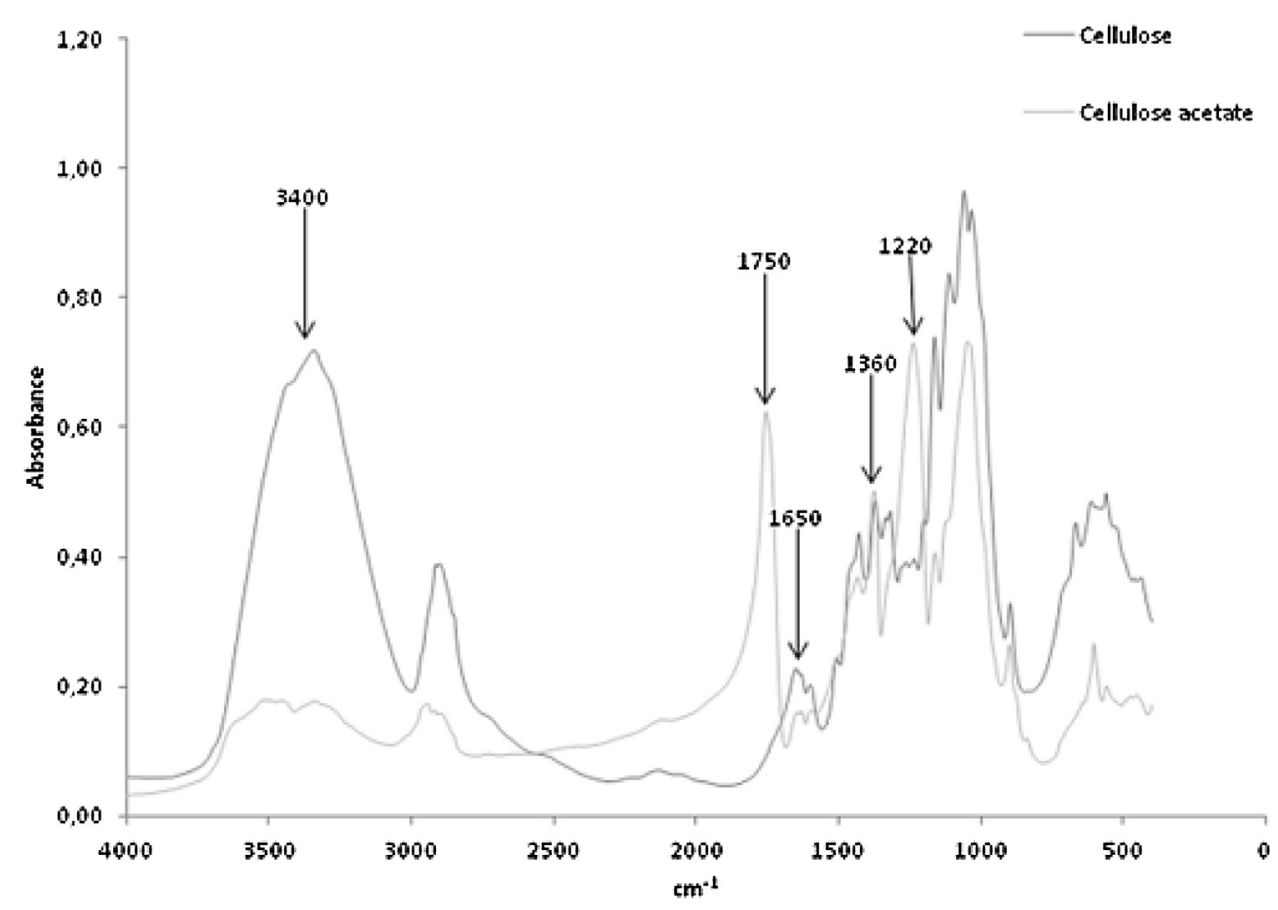

Fig. 1. FTIR of the cellulose and the cellulose acetate synthesized from sugarcane bagasse cellulose.

the parameters of membrane synthesis (Table 1), it can be implied that the time of solvent evaporation was the parameter that most influenced the formation of the porous in the membrane structures. A lower solvent evaporation time led to a higher porosity, which explains the highest porosity of M2 and the lowest porosity of M4. A lower solvent evaporation time probably did not permit the rearrangement of the cellulose acetate chains, leading to the formation of the porous (spaces between the polymeric chains). Higher time of solvent evaporation led to higher level of cellulose acetate chain compactation, affecting negatively the porous formation.

Due to the phase inversion, the liquid-liquid interaction between the solvent (dichloromethane) and the non-solvent (water) occurs when the membrane is located in the coagulation bath. If this interaction is strong, there is not porous formation. In other words, if there is not the liquid-liquid interaction, there is not formation of porous. Thus, it is necessary that the solvent and the non-solvent present different chemical properties, mainly polarity, to allow the formation of the membrane porous.

As M2 and M4 presented a very different porosity and were synthesized with the same temperature for the coagulation bath, it can be affirmed that this parameter did not affect the formation of the porous. Although it has been demonstrated that the temperature and the type of the coagulation bath influences strongly the porous formation (Mulder, 1991), this phenomenon was not verified in the present work. The liquid-liquid interaction between the solvent and the non-solvent occurs when the membrane is located in the coagulation bath. If this interaction is strong, porous are not generated. Thus, it is necessary that the solvent and the non-solvent present different chemical properties, mainly polarity, to allow the formation of the membrane porous. In relation to the temperature of the coagulation bath, probably, the low difference between the two coagulation bath temperatures applied in the study of membrane synthesis did not permit the verification of the coagulation bath temperature influence. In other words, the effect of the temperature in the porous formation was practically the same in all cases.

\subsection{3. $D S C$}

The thermal properties of the membranes were evaluated by DSC and the graphics are exhibited in Fig. 4. Four main thermal events were detected for all membranes: and endothermic peak around $30^{\circ} \mathrm{C}$ which represents the glass transition temperature $\left(T_{g}\right)$ of the membranes, an exothermic peak around $220^{\circ} \mathrm{C}$ attributed to the crystallization process of the cellulose acetate amorphous portion during the scan, and endotherm at approximately $265^{\circ} \mathrm{C}$ due to the fusion of cellulose acetate, and exothermic peak around $370^{\circ} \mathrm{C}$ relative to the degradation of acetylated lignin, hemicellulose derivatives and cellulose acetate polymeric chain.

The $T_{g}$ for a pure cellulose acetate membrane is in the range of $55-85^{\circ} \mathrm{C}$ (Zafar, Ali, Khan, Jamil, \& Butt, 2012), higher than the $\mathrm{Tg}$ presented by the membranes of this work. This means that the presence of lignin and hemicellulose provided the decrease in $T_{g}$ value. These authors used a pure cellulose acetate from wood to synthesize membranes and obtained a $\mathrm{T}_{\mathrm{g}}$ of $66^{\circ} \mathrm{C}$. As demonstrated in viscosity analysis, the polymeric chain of sugarcane bagasse cellulose is shorter than the wood cellulose. Hence, the lower size of the sugarcane bagasse cellulose polymeric chain also interfered negatively in the $\mathrm{T}_{\mathrm{g}}$ value.

The four membranes presented a degradation temperature around $370^{\circ} \mathrm{C}$. However, the thermal degradation of pure CA membrane is at $260^{\circ} \mathrm{C}$ (Lucena, Alencar, Mazzeto, \& Soares, 2003). Thus, despite decreasing the $T_{g}$ value, the presence of lignin and hemicellulose contributed to the increase of the membrane thermal resistance.

The principal difference amongst the DCS results of the membranes was the temperature in which the thermal events occurred. Membranes M3 and M4 achieved higher temperatures for crystallization, fusion and degradation processes than membranes M1 and M2. The difference in the synthesis of these membranes was the time of solvent evaporation, M3 and M4 were synthesized using a higher solvent evaporation time. Since the temperature for the occurrence of a thermal process is proportional to the energy necessary to disrupt the interaction amongst the polymeric chains, it can be interpreted that a higher time of solvent evaporation supplies 

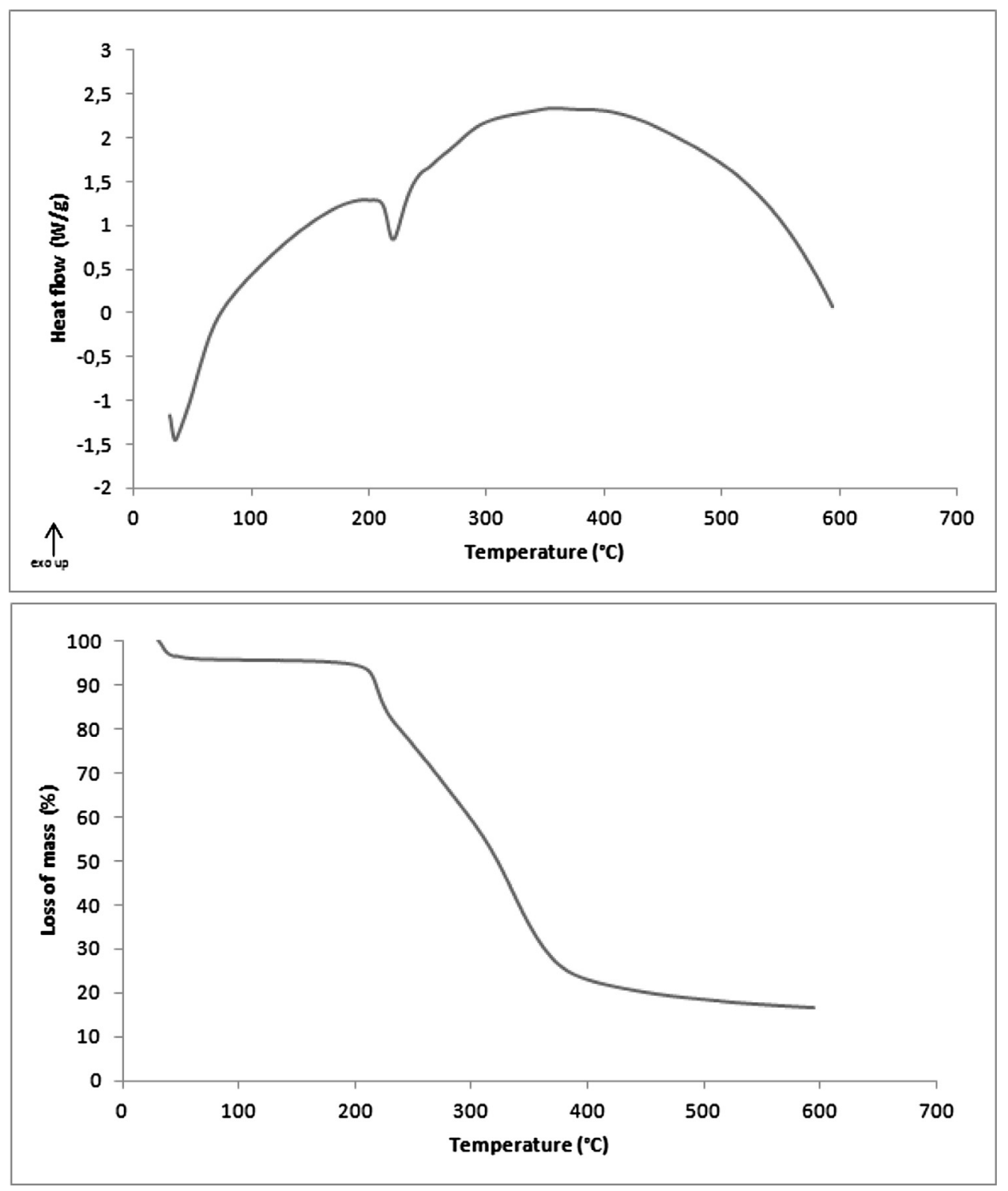

Fig. 2. DSC (top) and TGA (bottom) analysis of cellulose acetate.

a higher compaction of the polymeric chains and, consequently, increased the interaction amongst them.

\subsubsection{Flux of water vapor}

The vapor water flux was determined using the condition of stationary state in curves of water loss as a function of time, and the flux was calculated using the data in Table 2.

All membranes were able to permeate vapor water, but the membranes that were synthesized using higher time for solvent evaporation (M3 and M4) obtained the highest fluxes. This result demonstrates that a higher time of solvent evaporation resulted in the production of a membrane with higher uniformity, which facilitated the permeation of the water vapor.

The results of water vapor flux are higher than reported to a cellulose acetate membrane produced from sugarcane bagasse $\left(9.10 \times 10^{-7} \mathrm{~g} \mathrm{~s}^{-1} \mathrm{~cm}^{-2} \mu \mathrm{m}\right)$ (Rodrigues Filho et al., 2000), and to a cellulose acetate membrane produced from mango seed $\left(3.11 \times 10^{-5} \mathrm{~g} \mathrm{~s}^{-1} \mathrm{~cm}^{-2} \mu \mathrm{m}\right)$ (Meireles et al., 2010), indicating that the conditions employed to synthesize membranes in our work were very appropriate. Considering the characterization and application results achieved by the membranes, the best conditions were those used to prepare membrane M4. This was the membrane that reached the highest flux of water vapor and presented the highest thermal resistance.

\section{Conclusions}

In conclusion, results showed that it was possible to synthesize cellulose acetate from sugarcane bagasse with the investigated synthesis conditions. Lignin and hemicellulose were not totally removed in the cellulose extraction process, but this fact did not affect negatively the properties of the cellulose acetate. CA presented a percentage of acetyl groups of $43.50 \%$ and a substitution degree of 2.52, i.e., triacetate cellulose was synthesized. FTIR analysis confirmed the replacement of free $\mathrm{OH}$ groups by acetyl groups in the synthesis of CA. The presence of impurities (lignin and hemicellulose) in CA structure did not affect its thermal properties when compared to a $100 \%$ pure $C A$.

In relation to the membranes, the time of solvent evaporation was the synthesis parameter that most influenced the thermal properties and performance of the membranes. Membranes M3 and M4, which were prepared with the highest employed time 

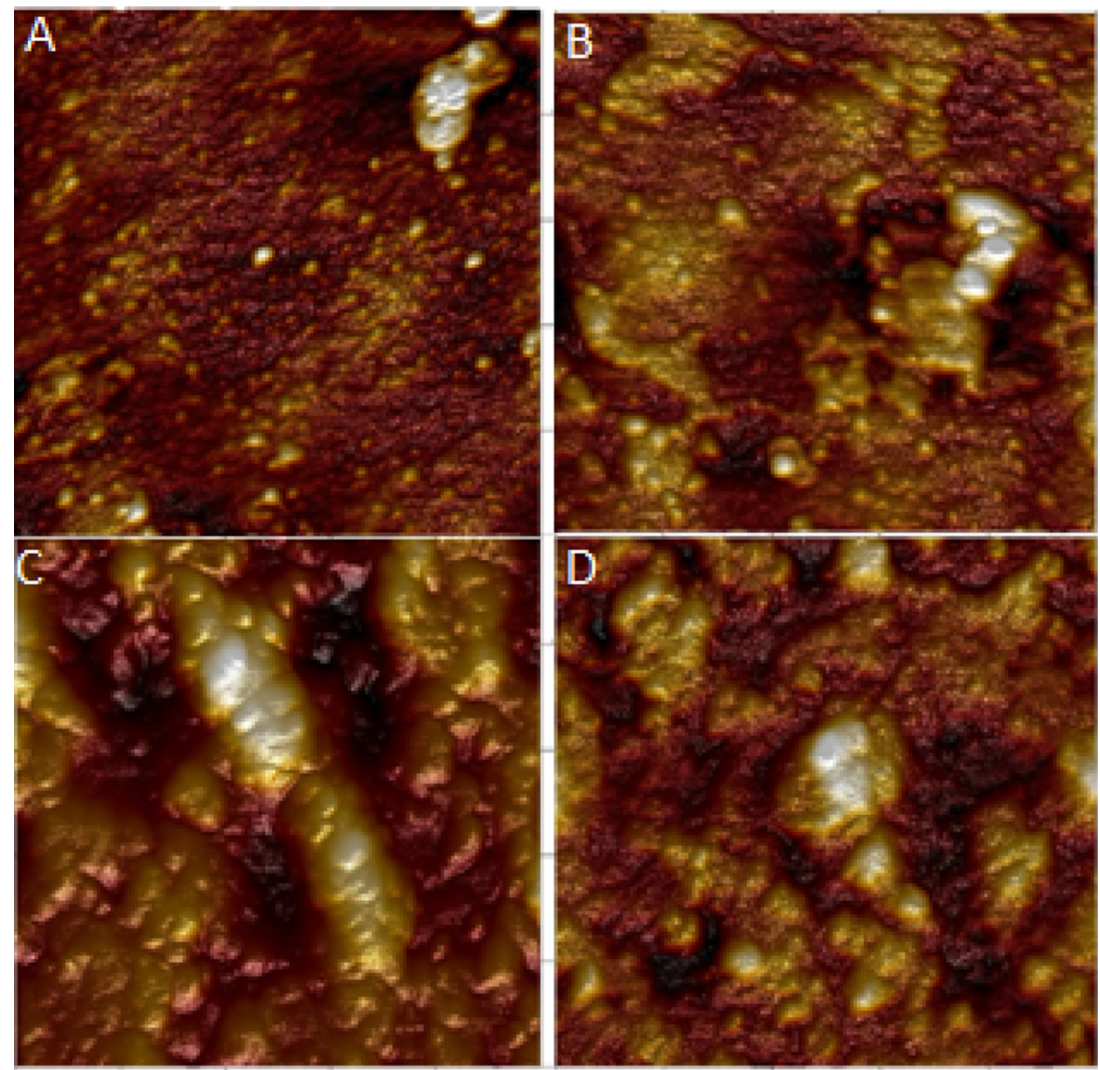

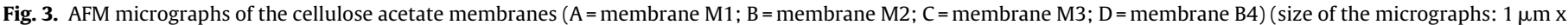
$1 \mu \mathrm{m})$.

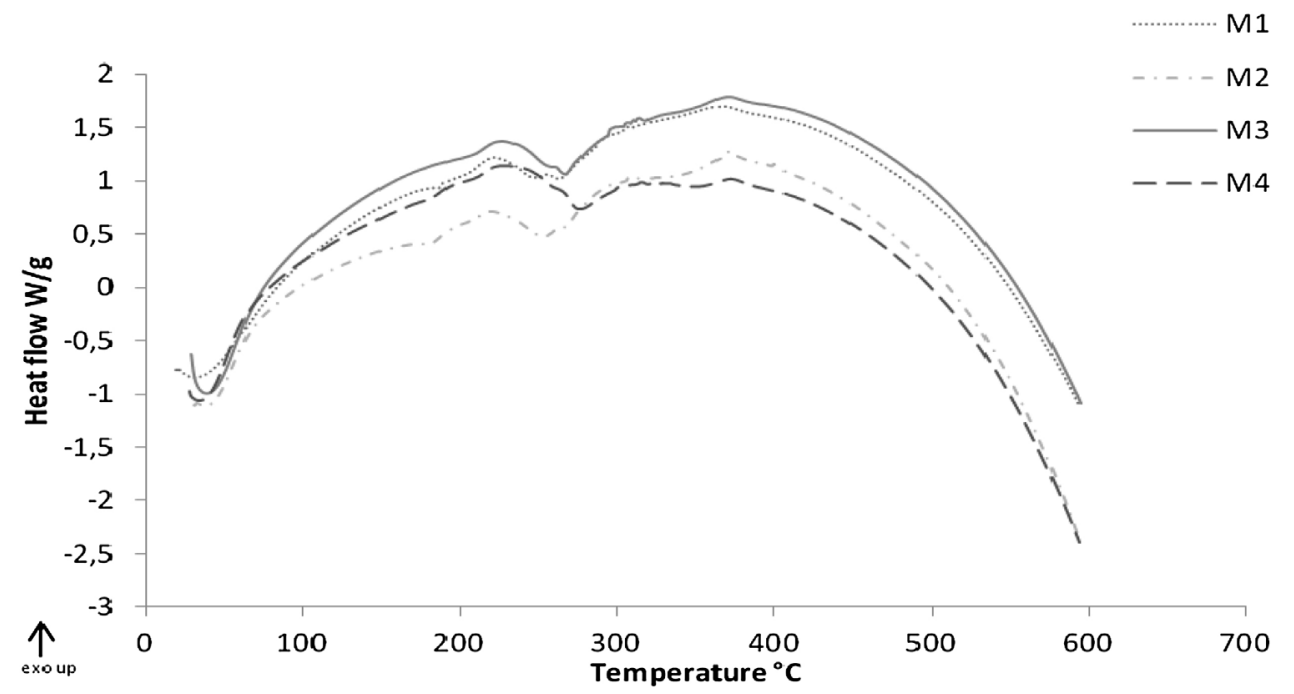

Fig. 4. DSC thermograms of the cellulose acetate membranes.

Table 2

Flux of water vapor of the cellulose acetate membranes.

\begin{tabular}{|c|c|c|c|c|c|}
\hline Membrane & $\begin{array}{l}\alpha \\
\left(\mathrm{mgh}^{-1}\right)\end{array}$ & $\begin{array}{l}(1 / \mathrm{A}) \\
\left(\mathrm{cm}^{-2}\right)\end{array}$ & $\begin{array}{l}\mathrm{J}=\alpha^{*} 1 / \mathrm{A} \\
\left(\mathrm{mg} \mathrm{h}^{-1} \mathrm{~cm}^{-2}\right)\end{array}$ & $\begin{array}{l}\mathrm{L} \\
(\mu \mathrm{m})\end{array}$ & $\begin{array}{l}\mathrm{JL} \\
\left(\mathrm{g} \mathrm{s}^{-1} \mathrm{~cm}^{-2} \mu \mathrm{m}\right)\end{array}$ \\
\hline M1 & 15.80 & 0.175 & 2.76 & 50 & $3.83 \times 10^{-5}$ \\
\hline M2 & 16.50 & 0.175 & 2.88 & 50 & $4.00 \times 10^{-5}$ \\
\hline M3 & 28.15 & 0.175 & 4.91 & 50 & $6.82 \times 10^{-5}$ \\
\hline M4 & 33.57 & 0.175 & 5.86 & 50 & $8.14 \times 10^{-5}$ \\
\hline
\end{tabular}

( $\alpha=$ slope of the water loss curves; $A=$ membrane surface area; $\mathrm{J}=$ flux of water vapor; $\mathrm{L}=$ membrane thickness; $\mathrm{JL}=$ flux normalized by thickness). 
of solvent evaporation (10 min), achieved the highest water vapor fluxes and the highest thermal resistance. Moreover, it was verified that the presence of small amounts of lignin and hemicellulose increased the thermal resistance of the membranes.

Analyzing individually the results obtained by the four membranes, membrane M4 presented the best performance, principally the flux of water vapor $\left(8.14 \times 10^{-5} \mathrm{~g} \mathrm{~s}^{-1} \mathrm{~cm}^{-2} \mu \mathrm{m}\right)$, and so, the conditions in which it was synthesized were the best conditions for membrane preparation: $3 \%(\mathrm{w} / \mathrm{v})$ of polymer/solvent relation, $10 \mathrm{~min}$ of solvent evaporation time, and $20^{\circ} \mathrm{C}$ as temperature for the coagulation bath.

Based on the results achieved in this work, it can be inferred that the membranes synthesized from sugarcane bagasse can be utilized in technological applications such as desalination, gas separation or drug release. One of the main advantages of these membranes is that they can present lower final cost than membranes synthesized from a synthetic polymer for being synthesized from a cheap and renewable raw material (sugarcane bagasse).

\section{Acknowledgments}

The authors acknowledge to Usina de Açúcar, Álcool e Biodiesel Vale do Rosário for sugarcane bagasse supply and FAPESP [grant number 2010/20396-8] for the financial support.

\section{References}

Barud, H. S., Araújo Junior, A. M., Santos, D. B., Assunção, R. M. N., Meireles, C. S., Cerqueira, D. A., et al. (2008). Thermal behavior of cellulose acetate produced from homogeneous acetylation of bacterial cellulose. Thermochimica Acta, 471, 61-69.

Bizzo, W. A., Lenço, P. C., Carvalho, D. J., \& Veiga, J. P. (2014). The generation of residual biomass during the production of bio-ethanol from sugarcane: Its characterization and its use in energy production. Renewable E'Sustainable Energy Reviews, 29, 589-603.

Buchanan, C. M., Gardner, R. M., \& Komarek, R. J. (1993). Aerobic biodegradation of cellulose acetate. Journal of Applied Polymer Science, 47, 1709-1719.

Candido, R. G. (2015). Production of membranes from sugarcane bagasse and its application in the detoxification of hemicellulosic hydrolisate. PhD Thesis. Engineering School of Lorena - University of São Paulo.

Cao, Y., Wu, J., Meng, T., Zhang, J., He, J., \& Li, H. (2007). Acetone-soluble cellulose acetates prepared by one-step homogeneous acetylation of cornhusk cellulose in an ionic liquid 1-allyl-3-methylimidazolium chloride ( $\mathrm{AmimCl})$. Carbohydrate Polymers, 69, 665-672.

Cheng, H. N., Dowd, M. K., Selling, G. W., \& Biswas, A. (2010). Synthesis of cellulose acetate from cotton byproducts. Carbohydrate Polymers, 80, 449-452.

Cherubini, F. (2010). The biorefinery concept: Using biomass instead of oil for producing energy and chemicals. Energy Conversion and Management., 51, $1412-1421$.

Chheda, J. N., Huber, G. W., \& Dumesic, J. A. (2007). Liquid-phase catalytic processing of biomass-derived oxygenated hydrocarbons to fuels and chemicals. Angewandte Chemical International Edition, 46, 7164-7183.

Dantas, G. A., Legey, L. F. L., \& Mazzone, A. (2013). Energy from sugarcane bagasse in Brazil: An assessment of the productivity and cost of different technological routes. Renewable \&' Sustainable Energy Reviews, 21, 356-364.

Ek, M., Gellerstedt, G., \& Henriksson, G. (2009). Pulp and paper chemistry and technology. Berlin: Walter De Gruyter GmbH \& Co.

Fahd, S., Fiorentino, G., Mellino, S., \& Ulgiati, S. (2012). Cropping bioenergy and biomaterials in marginal land: The added value of the biorefinery concept. Energy, 37, 79-93.

Fan, G., Liao, C., Fang, T., Luo, S., \& Song, G. (2014). Amberlyst 15 as a new and reusable catalyst for the conversion of cellulose into cellulose acetate. Carbohydrate Polymers, 112, 203-2009.

Fischer, S., Thummler, K., Volkert, B., Hettrich, K., Schmidt, I., \& Fischer, K. (2008). Properties and applications of cellulose acetate. Macromolecular Symposia, 262, 89-96.

Gaana, S., Mauclaire, L., Ruer, P., Salimova, V., Tran, T.-T., \& Heuberger, M. (2011). Thermal degradation of cellulose acetate in presence of bis-phosphoramidates. Journal of Analytical Applied Pyrolisis, 90, 33-41.

Gedon, S., \& Fengl, T. (1993). J. I. Kroschwitz, \& M. Howe-Grant (Eds.), Kirk-Othmer encyclopedia of chemical technology (Vol. 5) (pp. 496-563). New York: Wiley.

Ghaemi, N., Madaeni, S. S., Alizadeh, A., Darei, P., Vatanpour, V., \& Falsafi, M. (2012). Fabrication of cellulose acetate/sodium dodecyl sulfate nanofiltration membrane: Characterization and performance in rejection pesticides. Desalination, 290, 99-106.

Habib, Y., Lucia, L. A., \& Rojas, O. J. (2010). Cellulose nanocrystals: Chemistry, self-assembling and applications. Chemical Reviews, 110, 3479-3500.
Haddad, R., Ferjani, E., Roudesli, M. S., \& Deratani, A. (2004). Properties of cellulose acetate nanofiltration membranes: Application to brackish water desalination. Desalination, 167, 403-409.

He, J., Zhang, M., Cui, S., \& Wang, S. (2009). High-quality cellulose triacetate prepared from bamboo dissolving pulp. Journal of Applied Polymer Science, 113, 456-465.

Heguaburu, V., Franco, J., Reina, L., Tabarez, C., Moyna, G., \& Moyna, P. (2012). Dehydration of carbohydrates to 2-furaldehydes in ionic liquids by catalysis with ion exchange resins. Catalysis Communication, 27, 88-91.

Jiang, L.-Q., Fang, Z., Li, X.-K., Luo, J., \& Fan, S. P. (2013). Combination of dilute acid and ionic liquid pretreatments of sugarcane bagasse for glucose by enzymatic hydrolysis. Process Biochemistry, 48, 1942-1946.

Kamal, H., Abd-Elrahim, F. M., \& Lotfy, S. (2014). Characterization and some properties of cellulose acetate-co-polyethylene oxide blends prepared by the use of gamma irradiation. Journal of Radiation Research and Applied Science, 7. $146-153$

Kelley, S. S., Puleo, A. C., \& Paul, D. R. (1989). The effect of degree of acetylation on gas sorption and transport behavior in cellulose acetate. Journal of Membrane Science, 47, 301-332.

Kvarnlof, N., Germgard, U., Jonsso, L., \& Soderlund, C. A. (2006). Enzymatic treatment to increase the reactivity of a dissolving pulp for viscose production. Appita Journal, 59, 242-246.

Lavoine, N., Desloges, I., Dufresne, A., \& Bras, J. (2012). Microfibrillated cellulose Its barrier properties and applications in cellulosic materials: A review. Carbohydrate Polymers, 90, 735-764.

Lee, J. W., Kim, J. Y., Jang, H. M., Lee, M. W., \& Park, J. M. (2015). Sequential dilute acid and alkali pretreatment of corn stover: Sugar recovery efficiency and structural characterization. Bioresource Technology, 182, 296-301.

Lewin, M., \& Goldstein, I. S. (1991). Wood structure and composition. New York: Marcel Dekker Inc.

Liao, Z., Klein, E., Poh, C. K., Huang, Z., Lu, J., Hardy, P. A., et al. (2005). Measurement of hollow fiber membrane transport properties in hemodialyzers. Journal of Membrane Science, 256, 176-183.

Lucena, M. C. C., Alencar, A. E. V., Mazzeto, S. E., \& Soares, S. A. (2003). The effect of additives on the thermal degradation of cellulose acetate. Polymer Degradation and Stabilization, 80, 149-155.

Luo, L., Voet, E. V., \& Huppes, G. (2010). Biorefining of lignocellulosic feedstock Technical, economic and environmental considerations. Bioresource Technology, 101, 5023-5032.

Mansourpanah, Y., Madaeni, S. S., Rahimpour, A., \& Farhadian, A. (2009). The effect of non-contact heating (microwave irradiation) and contact heating (annealing process) on properties and performance of polyethersulfone nanofiltration membranes. Applied Surface Science, 255, 8395-8402.

Martin, C., Volvok, P. V., Rozhkova, A. M., Puls, J., \& Sinitsyn, A. P. (2015). Comparative study of the enzymatic convertibility of glycerol- and dilute acid-pretreated sugarcane bagasse using Penicillium- and Trichoderma-based cellulase preparations. Industrial Crops \& Products, 77, 382-390.

Maryana, R., Marifatun, D., Wheni, A., Satriyo, K. W., \& Rizal, W. A. (2014). Alkaline pretreatment on sugarcane bagasse for bioethanol production. Energy Procedia $47,25-254$.

Meireles, C. S., Rodrigues Filho, G., Ferreira, M. F., Jr., Cerqueira, A. D., Assunção, R. M. N., Ribeiro, E. A. M., et al. (2010). Characterization of asymmetric membranes of cellulose acetate from biomass: Newspaper and mango seed. Carbohydrate Polymers, 80, 54-961.

Mulder, J. (1991). Basic principle of membrane technology. London: Kluwer Academic Publishers.

Puls, J., Wilson, S. A., \& Hölter, D. (2011). Degradation of cellulose acetate-based materials: A review. Journal of Polymer and Environment, 19, 152-165.

Rajesh, S., Maheswari, P., Senthilkumar, S., Jayalakshmi, A., \& Mohan, D. (2011). Preparation and characterization of poly(amide-imide) incorporated cellulose acetate membranes for polymer enhanced ultrafiltration of metal ions. Chemical Engineering Journal, 71, 33-44.

Rocha, G. J. M., Martín, C., Silva, V. F. N., Gómez, E. O., \& Gonçalves, A. R. (2012). Mass balance of pilot-scale pretreatment of sugarcane bagasse by steam explosion followed by alkaline delignification. Bioresource Technology, 111, 447-452.

Rodrigues Filho, G., Cruz, S. F., Pasquini, D., Cerqueira, D. A., Prado, V. S., \& Assunção, R. M. N. (2000). Water flux through cellulose triacetate films produced from heterogeneous acetylation of sugarcane bagasse. Journal of Membrane Science, 177, 225-231.

Rodrigues Filho, G., Silva, R. C., Meireles, C. D. S., Assunção, R. M. N., \& Otaguro, H. (2005). Water flux through blends from waste materials: Cellulose acetate (from sugar cane bagasse) with polystyrene (from plastics cups). Journal of Applied Polymer Science, 96, 516-522.

Rodrigues Filho, G., Monteiro, D. S., Meireles, C. D. S., Assunção, R. M. N., Cerqueira, D. A., Barud, H. S., et al. (2008). Synthesis and characterization of cellulose acetate produced from recycled newspaper. Carbohydrate Polymers, 73, 74-82.

Santos, V. E. N., Ely, R. N., Szklo, A. S., \& Mafrini, A. (2016). Chemicals: Electricity and fuels from biorefineries processing Brazil's sugarcane bagasse: Production recipes and minimum selling prices. Renewable E' Sustainable Energy Reviews, 53, 1443-1458.

Shaikh, H. M., Pandare, K. V., Nair, G., \& Varma, A. J. (2009). Utilization of sugarcane bagasse cellulose for producing cellulose acetates: Novel use of residual hemicellulose as plasticizer. Carbohydrate Polymers, 76, 23-29.

Silverstein, R. A., Chen, Y., Sharma-Shivappa, R. R., Boyette, M. D., \& Osborne, J. (2007). A comparison of chemical pretreatments methods for improving saccharafication of cotton stalks. Bioresource Technology, 98, 3000-3011. 
Steinmeier, H. (2004). Acetate manufacturing: Process and technology. Macromolecular Symposia, 208, 49-60.

Sun, X., Lu, C., Zhang, W., Tian, D., \& Zhang, X. (2013). Acetone-soluble cellulose acetate extracted from waste blended fabrics via ionic liquid catalyzed acetylation. Carbohydrate Polymers, 98, 405-411.

TAPPI. (1994). Technical Association of the Pulp and Paper Industry. TAPPI Standard Methods, T230 cm-94.

Thygesen, A., Oddershede, J., Lilholt, H., Thomsen, A. B., \& Stahl, K. (2005). On the determination of crystallinity and cellulose content in plant fibres. Cellulose, 12, 563-576.

Wang, F.-J., Yang, Y.-Y., Zhang, X.-Z., Zhu, T., Chung, T.-S., \& Moochhala, S. (2012) Cellulose acetate membranes for transdermal delivery of scopolamine base. Materials Science and Engineering: C, 20, 93-100.
Zafar, M., Ali, M., Khan, S. M., Jamil, T., \& Butt, M. T. Z. (2012). Effect of additives on the properties and performance of cellulose acetate derivative membranes in the separation of isopropanol/water mixtures. Desalination, 285, 359-365.

Zheng, Q. Z., Wang, P., Yang, Y. N., \& Cui, D. J. (2006). The relationship between porosity and kinetics parameter of membrane formation in PSF ultrafiltration membrane. Journal of Membrane Science, 286, 7-11.

\section{Further reading}

http://www.strategyr.com/Cellulose_Acetate_Market_Report. asp (Accessed 04.20.2016).

http://www.unicadata.com.br (Accessed 03.09.2015). 